\title{
Mathematical Modeling for Determination the Surface Charge Density and Eddy Current Problem Using the Haar Wavelet
}

\author{
Aldo Artur Belardi and Antonio H. Piccinini Neto \\ Electrical Department, Centro Universitário da FEI, Av. Humberto de Alencar Castelo Branco São Paulo 3972, Brazil
}

\begin{abstract}
This paper presents the mathematical basis, and some results, concerning the application of the Haar Wavelets as the expansion function in the Method of Moments. As an example, the surface charge density on a finite, thin plane plate, and the Eddy current problem, in which the main computational performance aspects are evaluated. Some computational optimization techniques are used, and their main aspects are stressed in the paper.
\end{abstract}

Key words: Moments, wavelets, Haar.

\section{Introduction}

Regarding the formulation, in order to illustrate the proposed methodology, the main theoretical aspects of the Method of Moments and of the Haar wavelets, are here presented. For simplification, the one and two dimension applications are taken into consideration.

\subsection{Method of Moments}

Although the Method of Moments is a known numerical one, and the complete description and details of this method have already been presented in many papers, in order to guide the reader through the overall method explanation, a brief summary is here shown. In a simplified way, it can be mentioned that the basis of the Method of Moments is the application of approximation functions, like the following one [1].

$$
\mathrm{f}(\mathrm{x})=\sum_{n} \alpha_{\mathrm{n}} \boldsymbol{L} \mathrm{g}_{\mathrm{n}}
$$

In the aforementioned expression, $\alpha_{\mathrm{n}}$ is the unknown coefficients, $g_{n}$ is the expansion function, the pulse or the Haar wavelets, and " $L$ " a

Corresponding author: Aldo Artur Belardi, Ph.D., research fields: numerical techniques, simulation problem, application in electrostatic, electromagnetic, wavelets, ILinear and non linear control problem, and EMC. mathematical operator. When the inner product, use a weighed function $W_{m}$, is carried out.

$$
\sum_{\mathrm{n}} \alpha_{\mathrm{n}}<\boldsymbol{L} \mathrm{g}_{\mathrm{n}}, \mathrm{W}_{\mathrm{m}}>=<\mathrm{f}, \mathrm{W}_{\mathrm{m}}>\text { para } \mathrm{m}=1,2 \ldots . . \mathrm{N}
$$

The previous expression can be represented in a matrix form by $[\boldsymbol{A}][\boldsymbol{\alpha}]=[\boldsymbol{B}]$, where $[\boldsymbol{\alpha}]$ is the unknown approximated solution coefficients column vector, and the matrixes $[\boldsymbol{A}]$ and $[\boldsymbol{B}]$ are given by:

$$
\left.[\mathrm{A}]=\left[\begin{array}{c}
<\boldsymbol{L g}_{1}, \mathrm{~W}_{1}>\ldots<\boldsymbol{L g}_{\mathrm{n}}, \mathrm{W}_{1}> \\
<\boldsymbol{L} \mathrm{g}_{1}, \mathrm{~W}_{2}>\ldots<\boldsymbol{L} \mathrm{g}_{\mathrm{n}}, \mathrm{W}_{2}> \\
<\boldsymbol{L} \mathrm{g}_{1}, \mathrm{~W}_{\mathrm{n}}>\ldots .<\boldsymbol{L} \mathrm{g}_{\mathrm{n}}, \mathrm{W}_{\mathrm{n}}>
\end{array}\right] ; \mathrm{B}\right]=\left[\begin{array}{c}
<\mathrm{f}, \mathrm{W}_{\mathrm{l}}> \\
<\mathrm{f}, \mathrm{W}_{2}> \\
<\mathrm{f}, \mathrm{W}_{\mathrm{n}}>
\end{array}\right](3)
$$

As a first application, the potential distribution on a finite and straight wire that can be calculated using the next equation is taken into consideration [2]:

$$
\mathrm{V}(\mathrm{x}, \mathrm{y}=0, \mathrm{z}=0)=\frac{1}{4 \pi \varepsilon} \int \frac{\rho\left(\mathrm{r}^{\prime}\right)}{\mathrm{R}\left(\mathrm{x}, \mathrm{x}^{\prime}\right)} \mathrm{dl}^{\prime}
$$

Thus making use of the method of moments, knowing the approximated solution function $f(x)$, the expansion function $g(x)$ and the weighting function $W(x)$, the potential on a finite straight wire can be estimated by the inner product of these functions:

$$
\mathrm{V}(\mathrm{x})=\langle\mathrm{g}, \mathrm{W}, \mathrm{f}\rangle \frac{1}{\mathrm{R}}=\int_{-\mathrm{a}}^{\mathrm{a}} \frac{\mathrm{g}(\mathrm{x}) \mathrm{W}(\mathrm{x}) \mathrm{f}(\mathrm{x})}{\mathrm{R}(\mathrm{x})} \mathrm{dx}
$$

Consequently, the surface density can be 
approximated by the $\mathrm{N}$ term expansion. If the wire is divided into uniform segments $\Delta=L / N$, after applying the weight delta function of Dirac $W_{\mathrm{m}}=\delta\left(x_{\mathrm{m}}-x^{\prime}\right)=1$, the inner product will become:

$$
\begin{aligned}
& \mathrm{V}(\mathrm{x})=\left\langle\mathrm{W}_{\mathrm{m}}, \mathrm{f}, \boldsymbol{L g}\right\rangle=\delta\left(\mathrm{x}-\mathrm{x}_{\mathrm{m}}\right) \mathrm{x} \\
& \mathrm{x} \frac{1}{4 \pi \varepsilon} \sum_{\mathrm{n}=1}^{\mathrm{N}} \alpha_{\mathrm{n}} \int_{0}^{\mathrm{L}} \frac{\mathrm{g}_{\mathrm{n}}\left(\mathrm{x}^{\prime}\right)}{\sqrt{\left(\mathrm{x}_{\mathrm{m}}-\mathrm{x}^{\prime}\right)^{2}+\mathrm{a}^{2}}} \mathrm{dx}
\end{aligned}
$$

Assuming the charges placed in the center of each subdivision in relation to the axis, substituting the values of $x$ by the distance of the charge position to the point $P\left(x_{\mathrm{m}}\right)$, we will have an integral that is only function of the $x$ '. For a fixed potential $V$, the equation can be represented, using matrix notation, by $\left[\boldsymbol{V}_{\mathbf{m}}\right]=$ $\left[Z_{\mathrm{mn}}\right]\left[\boldsymbol{\alpha}_{\boldsymbol{n}}\right]$, in which $\boldsymbol{Z}_{\mathbf{m n}}$ is defined by Ref. [3]:

$$
\mathrm{Z}_{\mathrm{mn}}=\int_{0}^{\mathrm{L}} \frac{\mathrm{g}_{\mathrm{n}}\left(\mathrm{x}^{\prime}\right)}{\sqrt{\left(\mathrm{x}_{\mathrm{m}}-\mathrm{x}^{\prime}\right)^{2}+\mathrm{a}^{2}}} \mathrm{dx^{ \prime }}
$$

The same approach can be used, if a two-dimensional application is considered. If a square plane plate is considered as an example, we should remember that the potential in a finite and very thin plane plate can be evaluated by Ref. [4]:

$$
\mathrm{V}(\mathrm{x}, \mathrm{y}, \mathrm{z}=0)=\frac{1}{4 \pi \varepsilon} \int_{-\mathrm{a}}^{\mathrm{a}} \mathrm{dx} \mathrm{x}^{\prime} \int_{-\mathrm{b}}^{\mathrm{b}} \mathrm{dy} \frac{\rho\left(\mathrm{x}^{\prime}, \mathrm{y}^{\prime}\right)}{\left[\left(\mathrm{x}-\mathrm{x}^{\prime}\right)^{2}+\left(\mathrm{y}-\mathrm{y}^{\prime}\right)^{2}\right]^{1 / 2}}
$$

Thus, after applying the method of the moments, knowing the function of the approximated solution $f(x, y)$, the expansion function $g(x, y)$ and the weighed function $W(x, y)$, the potential in a square plane plate, will be estimated by the inner product of these functions [5]:

$$
\mathrm{V}(\mathrm{x}, \mathrm{y})=\langle\mathrm{g}, \mathrm{W}, \mathrm{f}\rangle \frac{1}{\mathrm{R}}=\int_{-\mathrm{a}}^{\mathrm{a}} \frac{\mathrm{g}(\mathrm{x}, \mathrm{y}) \mathrm{W}(\mathrm{x}, \mathrm{y}) \mathrm{f}(\mathrm{x}, \mathrm{y})}{\mathrm{R}(\mathrm{x}, \mathrm{y})} \mathrm{dx}
$$

where,

$$
R(x, y)=\sqrt{\left(x-x^{\prime}\right)^{2}+\left(y-y^{\prime}\right)^{2}}
$$

Dividing the plate in equal segments and applying the weighed function as being the delta function of Dirac, we had that $\mathrm{W}_{\mathrm{m}}=\delta\left(\mathrm{x}-\mathrm{x}_{\mathrm{m}}\right) \delta\left(\mathrm{y}-\mathrm{y}_{\mathrm{m}}\right)$, being the inner product in the point given by:

$$
\begin{aligned}
& \mathrm{V}(\mathrm{x}, \mathrm{y}, \mathrm{z}=0)=\left\langle\mathrm{W}_{\mathrm{m}}, \mathrm{f}, \boldsymbol{L g}\right\rangle=\delta\left(\mathrm{x}-\mathrm{x}_{\mathrm{m}}\right) \delta\left(\mathrm{y}-\mathrm{y}_{\mathrm{m}}\right) \times \\
& \times \frac{1}{4 \pi \varepsilon} \int_{-\mathrm{a}}^{\mathrm{a}} \mathrm{d} \mathrm{x}^{\prime} \int_{-\mathrm{b}}^{\mathrm{b}} \mathrm{dy} \mathrm{y}^{\prime} \frac{\sum_{\mathrm{n}=1}^{\mathrm{N}} \alpha_{\mathrm{n}} \mathrm{g}_{\mathrm{n}}\left(\mathrm{x}^{\prime}, \mathrm{y}^{\prime}\right)}{\left[\left(\mathrm{x}_{\mathrm{m}}-\mathrm{x}^{\prime}\right)^{2}+\left(\mathrm{y}_{\mathrm{m}}-\mathrm{y}^{\prime}\right)^{2}\right]^{1 / 2}}
\end{aligned}
$$

Assuming the charges placed in the center of each sub division in relation to each axes, substituting the values of $x$ and $y$ by the distance of the charge position to the point $P\left(\mathrm{x}_{\mathrm{m}}, \mathrm{y}_{\mathrm{m}}\right)$, we will have an integral that is only function of $x^{\prime}$ and $y^{\prime}$. For a fixed potential $V$, the equation can be represented, using the matrix notation, by $\left[\boldsymbol{V}_{\mathbf{m}}\right]=\left[\boldsymbol{Z}_{\mathbf{m n}}\right]\left[\boldsymbol{\alpha}_{\mathbf{n}}\right]$, in which $\boldsymbol{Z}_{\mathbf{m n}}$ is defined by:

$$
\mathrm{Z}_{\mathrm{mn}}=\int_{-\mathrm{a}}^{\mathrm{a}} \mathrm{dx} \mathrm{x}^{\prime} \frac{\mathrm{b}}{\left.-\mathrm{b} 4 \pi \varepsilon \sqrt{\left(\mathrm{x}_{\mathrm{m}}-\mathrm{x}^{\prime}\right)^{2}+\left(\mathrm{x}_{\mathrm{m}}, \mathrm{y}^{\prime}\right)}-\mathrm{y}^{\prime}\right)^{2}} d \mathrm{y}^{\prime}
$$

\subsection{The Wavelets}

The analysis through the wavelets has been a good alternative in replacement of the classical analyses that utilize the Fourier series, chiefly when treating acoustic signals, interpreting seismic signals and in the solution of numerical methods applied to electromagnetism and electrostatics [6-8]. In general the wavelets can be defined by:

$$
\psi_{\mathrm{a}, \mathrm{b}}(\mathrm{x})=|\mathrm{a}|^{-1 / 2} \psi\left(\frac{\mathrm{x}-\mathrm{b}}{\mathrm{a}}\right) \mathrm{a}, \mathrm{b} \in \mathrm{R}, \mathrm{a} \neq 0
$$

Some kinds of wavelets are mentioned in the literature, making it possible for new family models to be built from them, which adapt more appropriately to each case. Figs. 1-3 represent the Modulated Gaussian or Morlet, Mexican Hat and Shannon wavelet which is expressed below. They also have greater difficulty in solving the equations that are the result of domestic product of whole double.

$$
\psi(x)=e^{i \omega_{0} x} e^{-x^{2} / 2}
$$

Fig. 2 represents the Mexican hat wavelet, which is expressed by:

$$
\psi(x)=\left(1-x^{2}\right) e^{-x^{2} / 2}
$$


Fig. 3 represents the Shannon wavelet, which is expressed by:

$$
\begin{aligned}
& \psi(x)=\frac{\sin \left(\frac{\pi x}{2}\right)}{\frac{\pi x}{2}} \cos \left(\frac{3 \pi x}{2}\right) \\
& \varphi(x)= \begin{cases}\frac{\sin (\pi x)}{\pi x}, & x \neq 0 \\
1 \quad, & x=0\end{cases}
\end{aligned}
$$

\subsection{The Haar Wavelets}

It was previously mentioned that many functions can be used as the expansion function. Among them, the pulse function, the truncate cosine function and the wavelets can be mentioned. Thus, after applying the method of the moments, and considering the Haar wavelets, a function $f(x, y)$ can be approximated by:

$$
\begin{aligned}
& f(x, y)=\sum_{k=-\infty}^{\infty} c_{k} \phi(x, y)+ \\
& +\sum_{j=-\infty}^{\infty} \sum_{k=-\infty}^{\infty} d_{j, k} f_{P}(x, y) \psi_{j, k}(x, y)
\end{aligned}
$$

In this equation " $j$ " and " $k$ " are the resolution and the translation levels, respectively.

Moreover, once the Haar wavelets, and the so-called mother function and scale function father are applied, the formulation, for two-dimensional applications, will result in a product combination, given by Refs. [9, 10]:

$$
\begin{gathered}
\phi^{(\mathrm{H})}(\mathrm{x})= \begin{cases}1 & 0 \leq \mathrm{x}<0.5, \text { and } \\
0 & \text { for other intervals }\end{cases} \\
\psi_{\mathrm{j}, \mathrm{k}}^{(\mathrm{H})}(\mathrm{x})=\left[\phi(\mathrm{x}) \psi(\mathrm{x}) \psi(2 \mathrm{x}) \psi(2 \mathrm{x}-1) \ldots \psi\left(2^{\mathrm{j}} \mathrm{x}-\mathrm{k}\right)\right] \\
\psi_{\mathrm{j}, \mathrm{k}}^{(\mathrm{H})}(\mathrm{y})=\left[\phi(\mathrm{y}) \psi(\mathrm{y}) \psi(2 \mathrm{y}) \psi(2 \mathrm{y}-1) \ldots \psi\left(2^{\mathrm{j}} \mathrm{y}-\mathrm{k}\right)\right] \\
\left\{\psi_{\mathrm{j}, \mathrm{k}}^{(\mathrm{H})}(\mathrm{x}),(\mathrm{y})\right\}=\phi(\mathrm{x}) \phi(\mathrm{y}), \phi(\mathrm{x}) \psi(\mathrm{y}), \ldots, \psi(2 \mathrm{x}-1) \psi(2 \mathrm{y}-1)
\end{gathered}
$$

\section{Formulation}

\subsection{Finite Straight}

Thus, making use of the Method of Moments, and the wavelets the Haar the potential on a finite straight wire can be estimated by the inner product of these functions. As an illustration, Fig. 4 represents the Haar function regarding one dimensions and two level of resolution considering the center of each load sharing in its position in relation to all the others and so on [11].

The mathematical solution is:

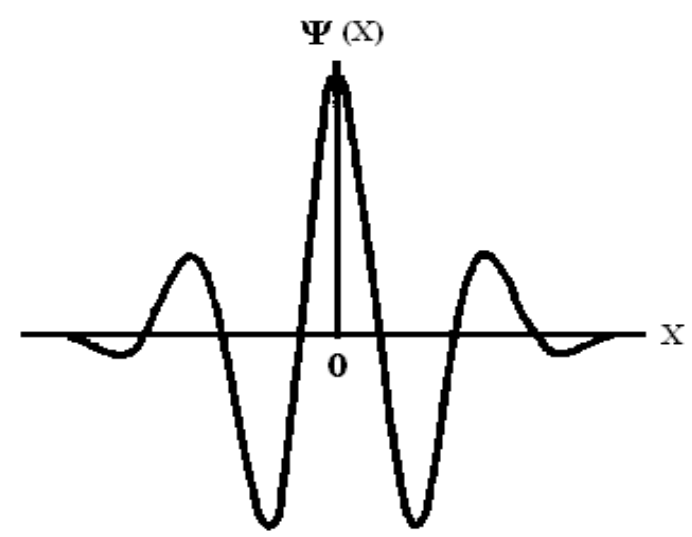

Fig. 1 Morlet.

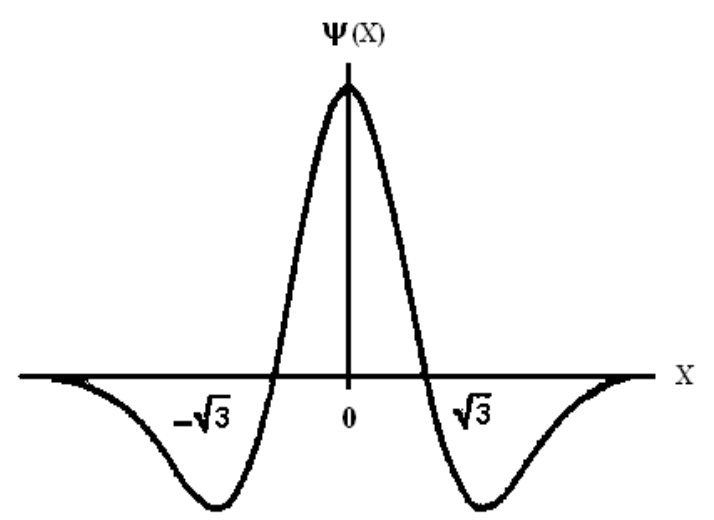

Fig. 2 Mexican hat.

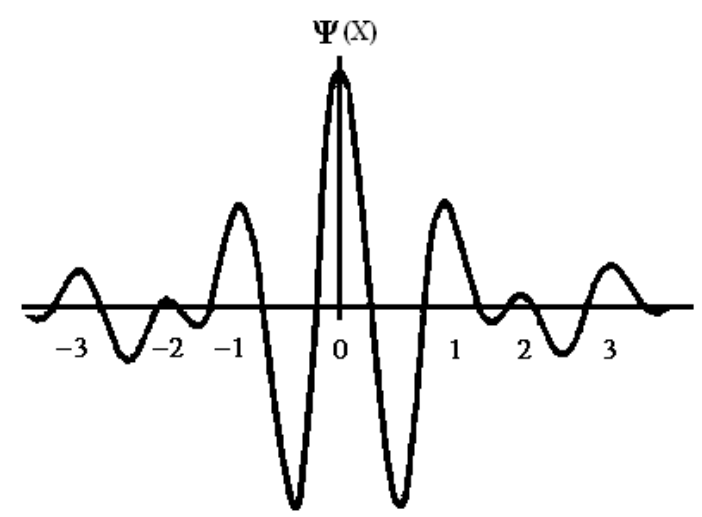

Fig. 3 The Shannon wavelet. 


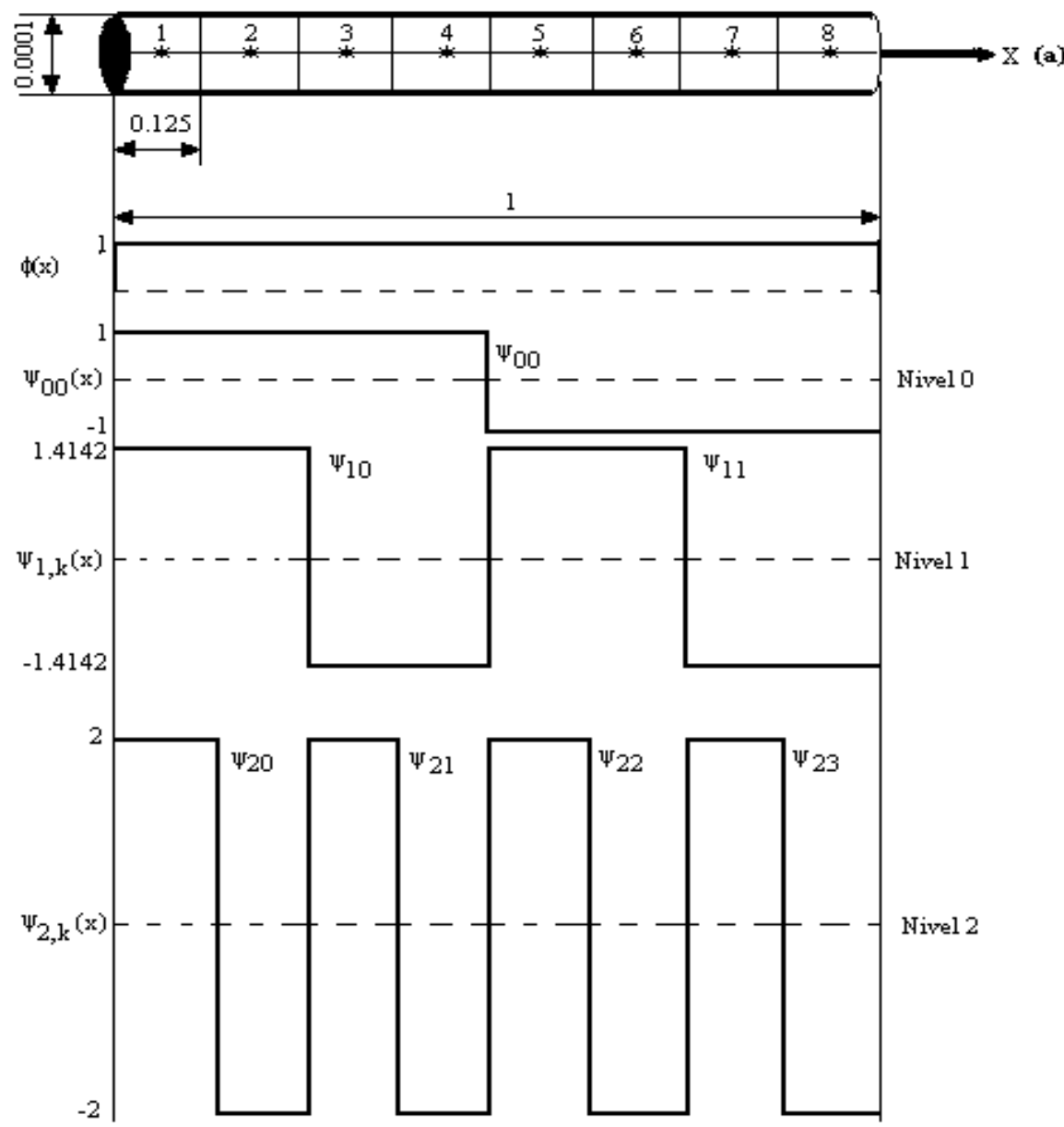

Fig. 4 The Haar wavelet in a finite straight.

$$
\begin{aligned}
& \mathrm{V}(\mathrm{r})=\frac{1}{4 \pi \varepsilon}\left[\int_{0}^{\mathrm{L}} \frac{\mathrm{c}_{0} \phi(\mathrm{x})}{\mathrm{R}\left(\mathrm{x}, \mathrm{x}^{\prime}\right)} \mathrm{dx}+\int_{0}^{\mathrm{L}} \frac{\sum_{\mathrm{n}=1}^{\mathrm{N}} \mathrm{c}_{\mathrm{j}, \mathrm{k}} \psi_{\mathrm{j}, \mathrm{k}}^{(\mathrm{H})}\left(\mathrm{x}^{\prime}\right)}{\mathrm{R}\left(\mathrm{x}, \mathrm{x}^{\prime}\right)} \mathrm{dx}\right](20) \\
& \mathrm{V}(\mathrm{r}) 4 \pi \varepsilon=\mathrm{c}_{0} \int_{0}^{\mathrm{L}} \frac{\phi(\mathrm{x})}{\sqrt{\left(\mathrm{x}-\mathrm{x}^{\prime}\right)^{2}+\mathrm{a}^{2}}} \mathrm{dx}+ \\
& +\left[\sum_{j=-\infty}^{\infty} \sum_{k=-\infty}^{\infty} c_{j, k} \int_{0}^{L} \frac{\psi_{j, k}^{(H)}\left(x^{\prime}\right)}{\sqrt{\left(x-x^{\prime}\right)^{2}+a^{2}}} d x\right]
\end{aligned}
$$

\subsection{The Thin Plane Plate}

The same approach can be used, if a two-dimensional application is considered.

It was previously mentioned that many functions can be used as the expansion function. Among them, the pulse function, the truncate cosine function and the

wavelets, the general aspects of the wavelets are shown.

As an illustration, Fig. 5 represents the Haar function regarding two dimensions and one level of resolution, for a point $P\left(x_{\mathrm{m}}, y_{\mathrm{m}}\right)$. In this case as the straight the same consideration put on the two axes (x and $y$ ) considering the center of each load sharing in its position in relation to all the others and so on. On the other hand, if the potential in a finite and very thin plane plate is taken into account as an application, it can be evaluated by Ref. [12]:

$$
\begin{aligned}
& \mathrm{V}(\mathrm{x}, \mathrm{y}) 4 \pi \varepsilon=\mathrm{a}_{\mathrm{j}} \mathrm{b}_{\mathrm{j}} \int_{-\mathrm{a}-\mathrm{b}}^{\mathrm{b}} \frac{\phi(\mathrm{x}, \mathrm{y})}{\sqrt{\left(\mathrm{x}_{\mathrm{m}}-\mathrm{x}^{\prime}\right)^{2}+\left(\mathrm{y}_{\mathrm{m}}-\mathrm{y}^{\prime}\right)^{2}}} \mathrm{dxdy}+ \\
& +\sum_{\mathrm{j}=-\infty}^{\infty} \sum_{\mathrm{k}=-\infty}^{\infty} \mathrm{a}_{\mathrm{j}, \mathrm{k}} \mathrm{b}_{\mathrm{j}, \mathrm{k}} \int_{-\mathrm{a}-\mathrm{b}}^{\mathrm{a}} \int_{\sqrt{\left(\mathrm{x}_{\mathrm{m}}-\mathrm{x}^{\prime}\right)^{2}+\left(\mathrm{y}_{\mathrm{m}}-\mathrm{y}^{\prime}\right)^{2}}}^{\mathrm{b}} d x d y
\end{aligned}
$$




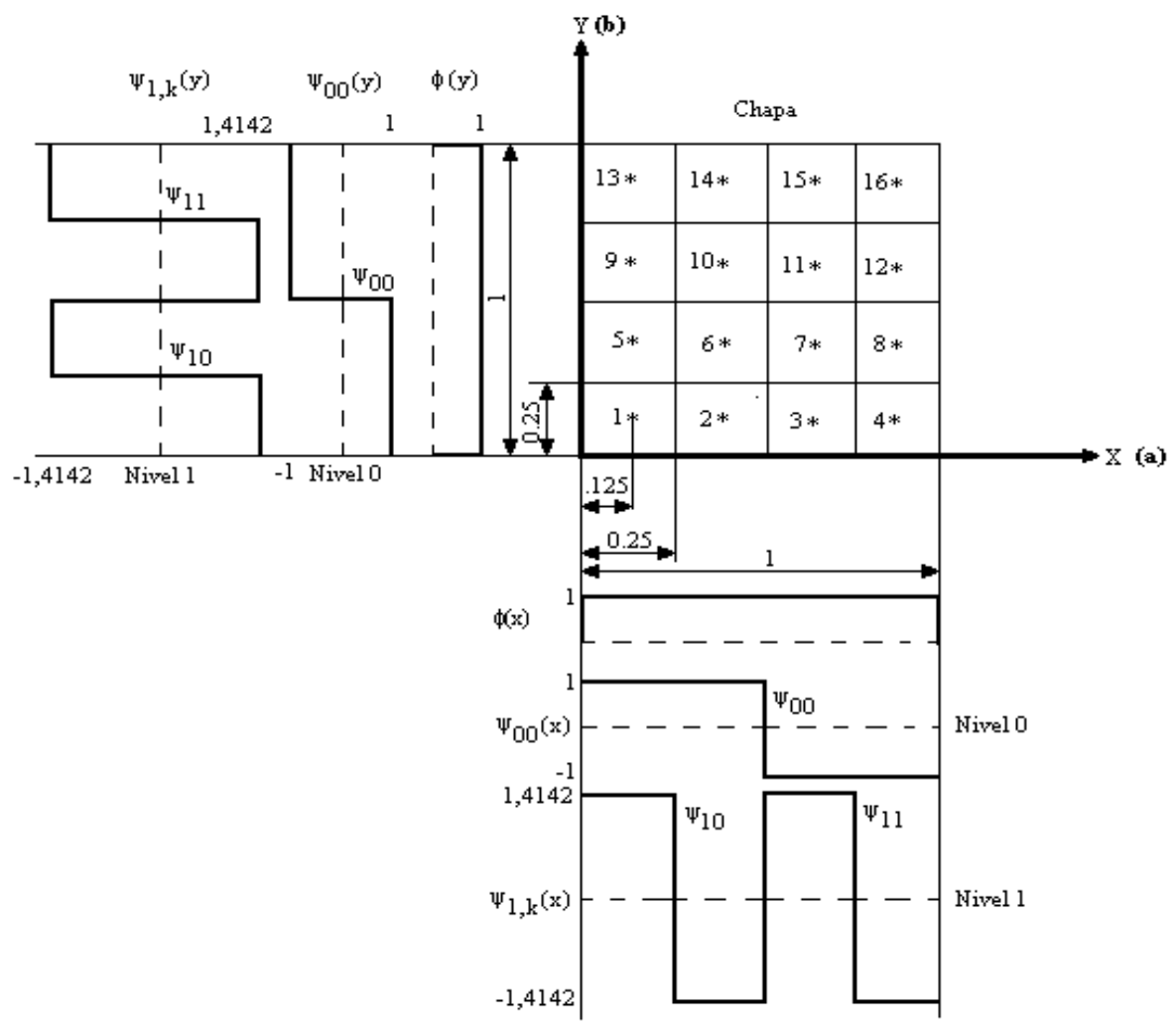

Fig. 5 Representation of the Haar function for two-dimensions and one level of resolution.

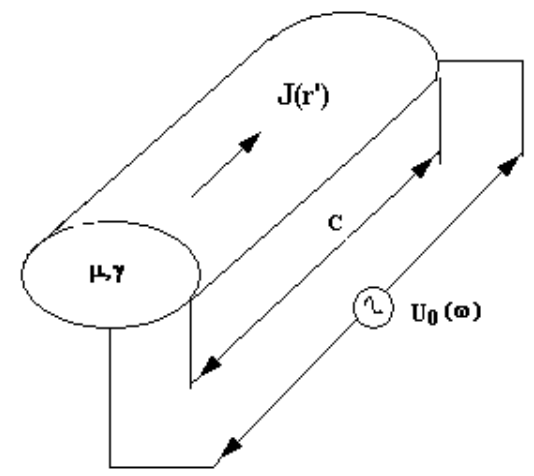

Fig. 6 Current in the conductor.

At each point we have

$$
\begin{aligned}
& \left\{\mathrm{c}_{\mathrm{k}} \psi_{\mathrm{j}, \mathrm{k}}^{(\mathrm{H})} \mathrm{d}_{\mathrm{j}, \mathrm{k}} \psi_{\mathrm{j}, \mathrm{k}\}}^{(\mathrm{H})}\right\}=\underset{0}{\mathrm{a}} \mathrm{b}_{0} \varphi(\mathrm{x}) \varphi(\mathrm{y})+\mathrm{a}_{0} \mathrm{~b}_{00} \varphi(\mathrm{x}) \psi_{00}(\mathrm{y})+\underset{0}{\mathrm{a}} \mathrm{b}_{10} \varphi(\mathrm{x}) \psi_{10}(2 \mathrm{y}) \\
& +\underset{0}{\mathrm{~b}} \mathrm{~b}_{11} \varphi(\mathrm{x}) \psi_{11}(2 \mathrm{y}-1)+\mathrm{a}_{00} \mathrm{~b}_{0} \psi_{00}(\mathrm{x}) \varphi(\mathrm{y})+\ldots+\mathrm{a}_{11} \mathrm{~b}_{11} \psi_{11}(2 \mathrm{x}-1) \psi_{11}(2 \mathrm{y}-1)
\end{aligned}
$$

\subsection{The Eddy Current Problem}

Let us consider the conducting wire to be composed of filaments, having their length is represented by $c$ and current density by $J\left(r^{\prime}\right)$, according to Fig. 6 .

The two-dimensional fields can be obtained by using two or more current distributions $J_{1}, J_{2}, \ldots$ on surface $S$, which is the interface between the conductor and the air.

By integrating it is possible to simplify the equations the most, so that there will not be complex integrals or approximations, as follows $[13,14]$ :

$$
\mathrm{A}(\mathrm{r})=\frac{\mu}{2 \pi \mathrm{s}} \int_{\mathrm{s}}\left(\mathrm{r}^{\prime}\right) \ln \frac{1}{\left|\mathrm{r}-\mathrm{r}^{\prime}\right|} d \mathrm{~s}^{\prime}
$$

In which $r$ and $r^{\prime}$ are respectively the origin and source points. The current density can be expressed by:

$$
\mathrm{J}(\mathrm{r})=\mathrm{J}_{\mathrm{e}}+\mathrm{J}_{\mathrm{s}}=-\mathrm{j} \omega \gamma \mathrm{A}(\mathrm{r})+\gamma \mathrm{U}_{0} / \mathrm{c}
$$

where, $U_{\mathbf{0}}$ is the applied voltage, $c$ and $s$ are the length and the sectional area of the conductor. Considering Fredholm integral, a second order equation is obtained:

$$
J(r)=\frac{j \omega \mu \gamma}{2 \pi} \int_{s} J\left(r^{\prime}\right) \ln \left|r-r^{\prime}\right| d s^{\prime}+J_{s}
$$

In which the math operator in the previous equation is given by: 


$$
\boldsymbol{L}=1-\frac{j \omega \mu \gamma}{2 \pi} \int_{\mathbf{s}} \ln \left|\mathrm{r}-\mathrm{r}^{\prime}\right| \mathrm{ds}^{\prime}
$$

By dividing the domain into $\mathrm{N}$ elements, the current density can be approximated by:

$$
J(r)=\sum^{n} J_{1} \psi_{1}
$$

By choosing the pulse as the expansion and weighting functions, the coefficients of matrix $\boldsymbol{A}$ can be determined by the following expression $[15,16]$ :

$$
\begin{aligned}
& \mathrm{a}_{\mathrm{mn}}=\left\langle\boldsymbol{L} \psi_{\mathrm{n}}, \mathbf{W}_{\mathrm{m}}\right\rangle=\int_{\mathrm{s}} \mathrm{P}_{\mathrm{m}}(\mathrm{x}, \mathrm{y}) \mathrm{ds}-\frac{\mathrm{j} \omega \mu \gamma}{2 \pi} \iint_{\mathrm{s} \mathrm{s}} \mathrm{P}_{\mathrm{m}}(\mathrm{x}, \mathrm{y}) \\
& * \ln \left[\left(\mathrm{x}_{\mathrm{m}}-\mathrm{x}_{\mathrm{n}}\right)^{2}+\left(\mathrm{y}_{\mathrm{m}}-\mathrm{y}_{\mathrm{n}}\right)^{2}\right]^{1 / 2} \mathrm{P}_{\mathrm{n}}(\mathrm{x}, \mathrm{y}) \mathrm{dsds}^{\prime}
\end{aligned}
$$

or

$$
\begin{aligned}
& \mathrm{a}_{\mathrm{mn}}=\Delta \mathrm{S}_{\mathrm{m}}-\frac{j \omega \mu \gamma}{2 \pi} \Delta \mathrm{S}_{\mathrm{m}} \Delta \mathrm{S}_{\mathrm{n}} * \\
& \ln _{\ln }\left[\left(\mathrm{x}_{\mathrm{m}}-\mathrm{x}_{\mathrm{n}}\right)^{2}+\left(\mathrm{y}_{\mathrm{m}}-\mathrm{y}_{\mathrm{n}}\right)^{2}\right]^{1 / 2} \\
& \mathrm{~b}_{\mathrm{mn}}=\left\langle\mathrm{J}_{\mathrm{s}}, \mathrm{W}_{\mathrm{m}}\right\rangle=\mathrm{J}_{\mathrm{s}} \Delta \mathrm{S}_{\mathrm{m}}
\end{aligned}
$$

Let us consider the sides of the elements resulting of the divisions performed in the superficial part of the conductor are square and defined as $h$.

By eliminating the other $\Delta S_{m}$ terms in the equations $a_{\mathrm{mn}}$ and $b_{\mathrm{m}}$, considering the relative positions of the different charges that will form the elements of matrix $\boldsymbol{A}$, and the relations $d / h>2$ and $d / h=1$, the following will be obtained:

$$
\begin{gathered}
a_{m n}=1-\frac{j \omega \mu \gamma}{4 \pi} h^{2} \ln \left[\left(x_{m}-x_{n}\right)^{2}+\left(y_{m}-y_{n}\right)^{2}\right] \\
a_{m n}=1-1,0065 \frac{j \omega \mu \gamma}{4 \pi} h^{2} * \\
* \ln \left[\left(x_{m}-x_{n}\right)^{2}+\left(y_{m}-y_{n}\right)^{2}\right]
\end{gathered}
$$

if $m=n$

$$
\mathrm{a}_{\mathrm{mn}}=1-\frac{\mathrm{j} \omega \mu \gamma}{2 \pi} \mathrm{h}^{2} \ln (0,44705 \mathrm{~h})
$$

By solving matrix $\boldsymbol{A}\{J\}=\left\{J_{\mathrm{s}}\right\}$ the current matrix will be obtained.

\section{Application}

\subsection{Finite Wire}

Applying the aforementioned formulation, we got some results related to applications: the first one related to a finite and straight wire, and another one regarding a thin plane plate. It is assumed in the applications a constant potential distribution equal to 1 V, conform Fig. 7.

Table 1 presents the results regarding the charge surface density on a $1.0 \mathrm{~m}$ straight wire, when it is divided in to 16 equal segments, as a function of the resolution (j) and the translation (k) levels. The result obtained with the various levels used with the Haar wavelet was also compared with a weighting of pulse function. Those results can be considered as the ones suitable to validate this approach [17].

\subsection{The Thin Plane Plate}

After applying the aforementioned formulation, some results were obtained. For example, Fig. 8 represents the surface charge density in a square plate $(1.0 \mathrm{~m} \times 1.0 \mathrm{~m})$, submitted to a potential of $1.0 \mathrm{~V}$. In this case, it was adopted 16 subdivision for each of the

\begin{tabular}{|c|c|c|c|c|}
\hline \multirow{3}{*}{ Point } & \multicolumn{4}{|c|}{ Expansion function } \\
\hline & \multicolumn{3}{|c|}{ Haar wavelet (level) } & \multirow[t]{2}{*}{ Pulse } \\
\hline & 2 & 3 & 4 & \\
\hline 1 & 8.835 & 9.376 & 9.957 & 9.957 \\
\hline 2 & 8.835 & 9.376 & 8.764 & 8.764 \\
\hline 3 & 8.835 & 8.274 & 8.411 & 8.411 \\
\hline 4 & 8.835 & 8.274 & 8.219 & 8.219 \\
\hline 5 & 7.970 & 8.059 & 8.102 & 8.102 \\
\hline$\ldots$ & $\cdots$ & $\cdots$ & $\cdots$ & $\cdots$ \\
\hline 12 & 7.970 & 8.059 & 8.102 & 8.102 \\
\hline 13 & 8.835 & 8.274 & 8.219 & 8.219 \\
\hline 14 & 8.835 & 8.274 & 8.411 & 8.411 \\
\hline 15 & 8.835 & 9.376 & 8.764 & 8.764 \\
\hline 16 & 8.835 & 9.376 & 9.957 & 9.957 \\
\hline
\end{tabular}
axes, and the level 5 of resolution was applied to the wavelets. Concerning the characteristic of the method, it should be emphasized that the application of the Haar wavelets originates scattered matrixes. Thus, we will have nulls coefficients that can result in a computing time reduction.

Table 2 presents the comparative results, regarding the computing time values function of the adopted axe

Table 1 Charge surface density $(\mathrm{pC} / \mathrm{m})$ on straight finite as a function of the resolutions levels. 

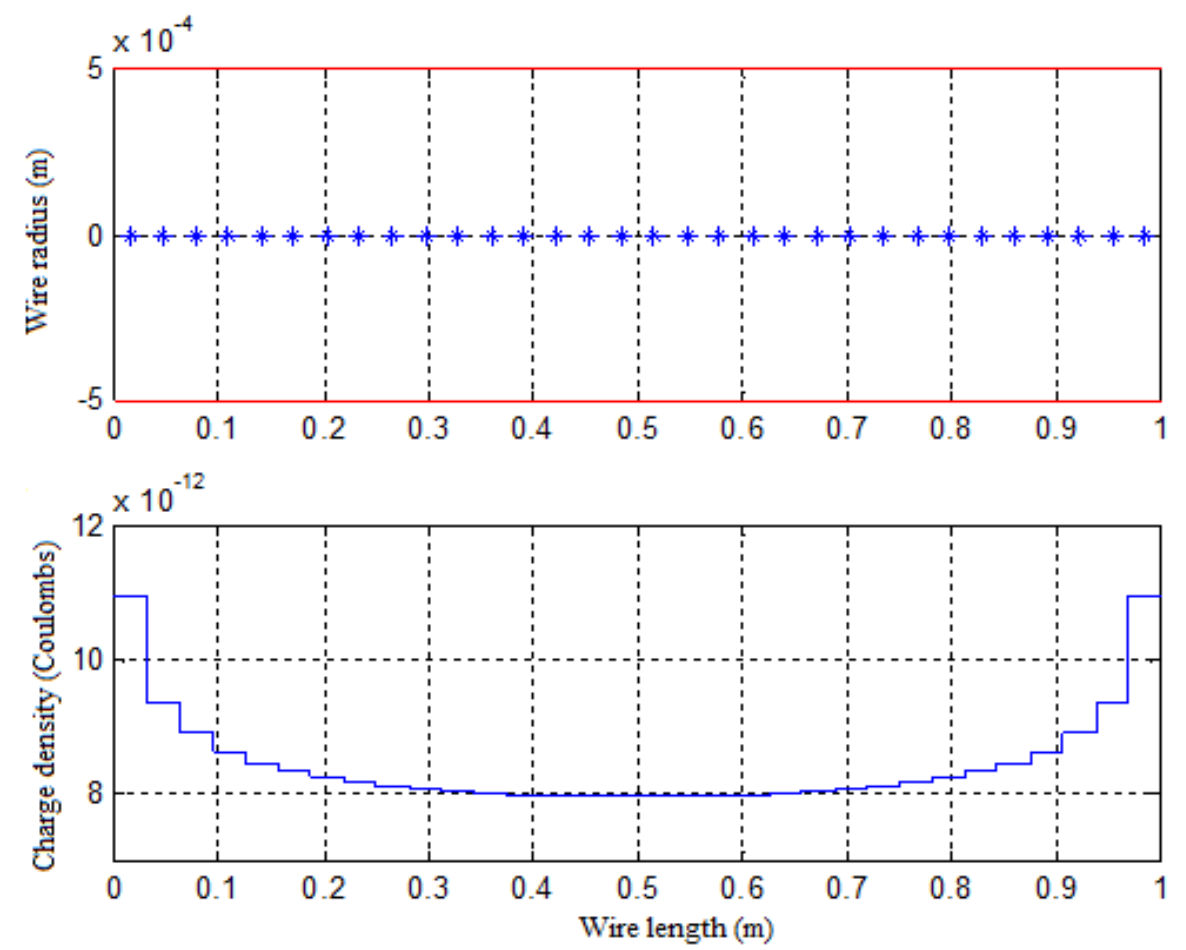

Fig. 7 The surface charge $(\mathrm{pC} / \mathrm{m})$ on a $1.0 \mathrm{~m}$ straight wire for 32 subdivisions.

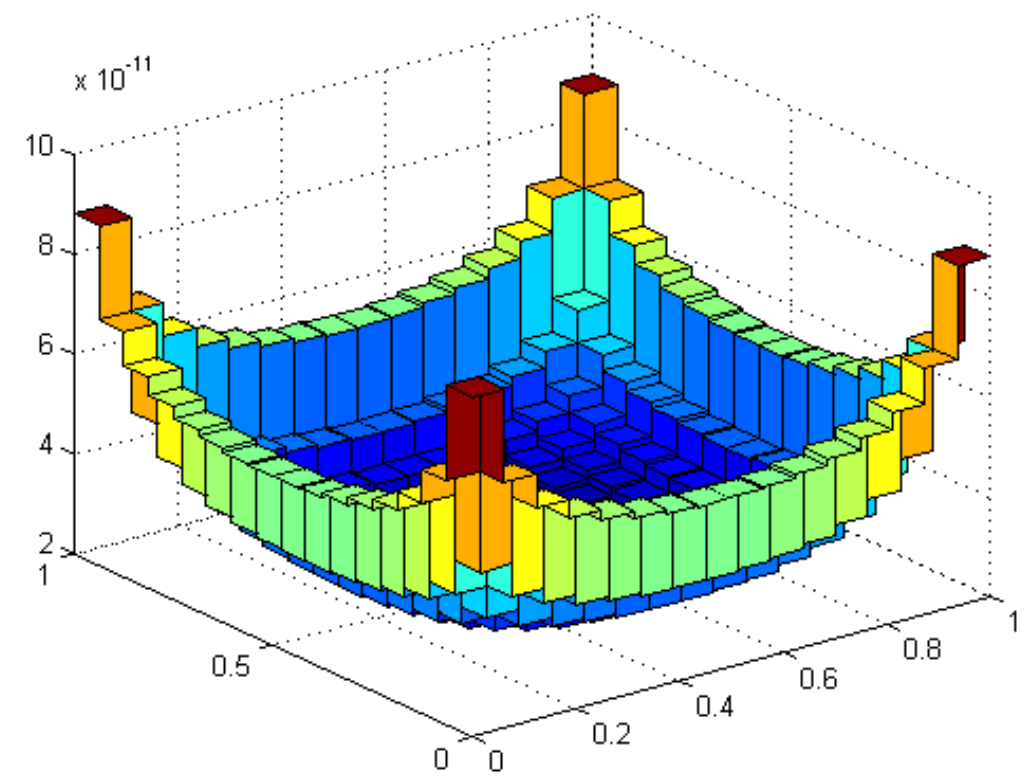

Fig. 8 The surface charge $(\mathrm{pC} / \mathrm{m})$ on a 1.0 by $1.0 \mathrm{~m}$ plate for 16 subdivisions.

division number, with or without applying the null value detection routine [18].

In applying for a finite flat plate, we measured the execution time of the program, varying the number of divisions in each of the axes, measuring both the amount held in floating point operations as the runtime. Table 3 shows the values obtained for the total execution time and the amount of floating point operations performed, using as expansion function the Haar wavelet. 
Taking advantage of the fact that the Haar matrix is sparse, we reduce the execution time of the program by entering a comparison that, when the null value is detected, the transaction between the arrays is performed. Table 4 presents the results comparing the values of the runtime and the number of floating point operations, with and without detection of null values.

According to the results, reduced on average $40 \%$ run time of the program. Fig. 9 (blue color) shows the values obtained for the runtime with and without detection of null values, depending on the number of divisions of finite flat plate.

When the plate was divided into 16 equal segments on each axis, a total of 256 coefficients were generated with $54 \%$ of them are zero. Taking advantage of the fact that the Haar matrix is sparse,

applying the matrix algebra we can write that

$$
\left[\mathrm{Z}_{\mathrm{mn}}\right] *[\rho]=[\mathrm{V}]
$$

Table 2 Computing time(s) function of the axe subdivisions and of the null value detection use.

\begin{tabular}{llll}
\hline Divisions & \multicolumn{2}{c}{ Computing time (s) } & Difference \\
\hline Plane Plate & Without & With & $(\%)$ \\
$4 \times 4$ & 0.321 & 0.25 & 22.12 \\
$8 \times 8$ & 7.931 & 5.488 & 30.80 \\
$16 \times 16$ & 451,960 & 222.60 & 50.75 \\
$32 \times 32$ & $27,273,738$ & $11,994,487$ & 56.02 \\
\hline
\end{tabular}

Table 3 Calculation floating point operations and the execution time depending on the number of divisions of the plate.

\begin{tabular}{lll}
\hline Divisions & Floating point operations & Runtime $(\mathrm{s})$ \\
\hline $4 \times 4$ & 29,075 & 0.321 \\
$8 \times 8$ & $1,236,699$ & 7.931 \\
$16 \times 16$ & $70,025,893$ & 451.96 \\
\hline
\end{tabular}

Table 4 Amount of floating point operations and execution time (s), depending on the number of divisions of the plate with and without detection of nulls.

\begin{tabular}{|c|c|c|c|c|c|}
\hline \multirow{3}{*}{ Div. } & \multicolumn{4}{|c|}{ Nulls value } & \multirow{3}{*}{$\begin{array}{l}\text { Diference } \\
(\%) \\
\text { Runtime }\end{array}$} \\
\hline & \multicolumn{2}{|c|}{ Without detection } & \multicolumn{2}{|c|}{ With detection } & \\
\hline & Flops operation & Runtime & Flops operation & Runtime & \\
\hline $4 \times 4$ & 29,075 & 0.321 & 25,491 & 0.250 & 22.12 \\
\hline $8 \times 8$ & $1,236,699$ & 7.931 & 843,483 & 5.488 & 30.80 \\
\hline $16 \times 16$ & $70,025,893$ & 451.96 & $39,748,261$ & 222.60 & 50.75 \\
\hline
\end{tabular}

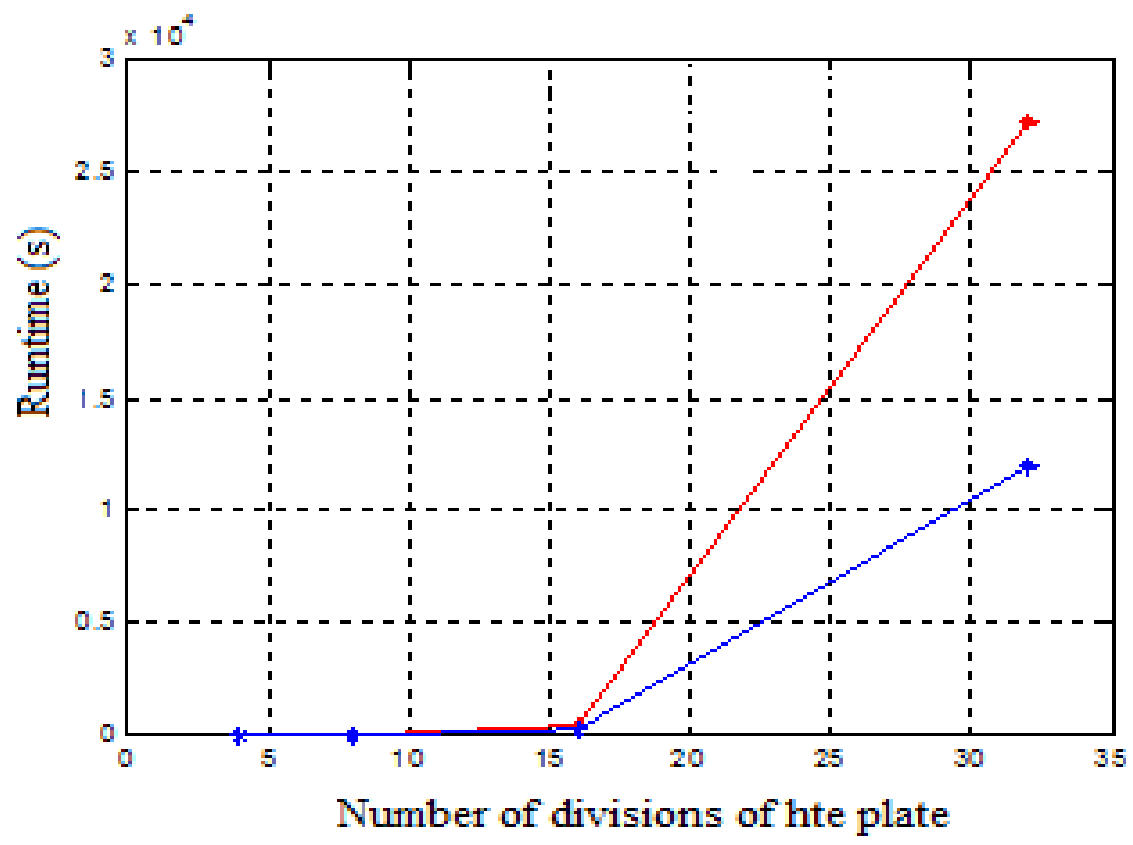

Fig. 9 The computing time (s) as a function of the subdivision axe number. 
where, $\boldsymbol{Z}_{\mathrm{mn}}$ is a square matrix that is not necessarily a scattered one, since it depends on the expansion function that was chosen. Thus, taking advantages of the fact that the Haar matrix is a scattered matrix, applying the matrix algebra, it will result [19]:

$$
\left[\mathrm{Z}_{\mathrm{mn}}^{\prime}\right] *\left[\rho^{\prime}\right]=\left[\mathrm{V}^{\prime}\right]
$$

else,

$$
\begin{gathered}
{\left[\mathrm{Z}_{\mathrm{mn}}^{\prime}\right]=[\mathrm{H}]\left[\mathrm{Z}_{\mathrm{mn}}\right]\left[\mathrm{H}^{\mathrm{T}}\right]} \\
{\left[\rho^{\prime}\right]=\left[\mathrm{H}^{\mathrm{T}}\right]^{-1} *[\rho] \text { and }\left[\mathrm{V}^{\prime}\right]=[\mathrm{H}][\mathrm{V}]} \\
{[\mathrm{H}] \times\left[\mathrm{Z}_{\mathrm{mn}}\right] \times\left[\mathrm{H}^{\mathrm{T}}\right] \times\left[\mathrm{H}^{\mathrm{T}}\right]^{-1} \times[\rho]=[\mathrm{H}] \times[\mathrm{V}]}
\end{gathered}
$$

As estimation, when the null value detection routine is carried using the null value detection routine. Fig. 10 represents the Haar matrix and Figs. 11 and 12 presents the $Z_{\mathrm{mn}}^{\prime}$ matrix configuration for the threshold equal to $0.01 \%$, and $0.05 \%$, respectively. The dark part is the no null values, resulting in a significant reduction in the elements of the matrix and allowing a reduction in execution time without affecting the end result.

Table 5 shows the computing time, when the threshold level and the axe subdivision number are taken into account.

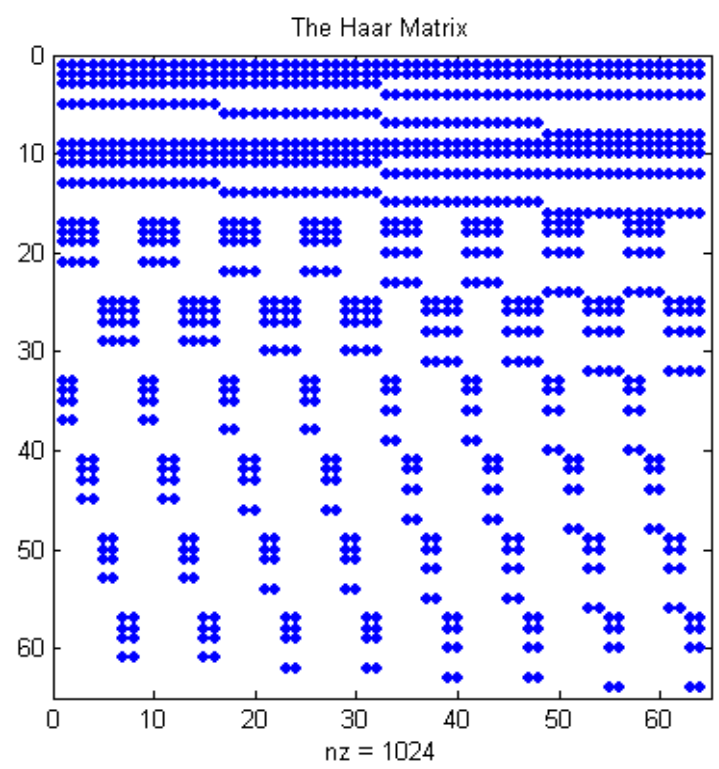

Fig. 10 The Haar matrix.
Fig. 13 represents the error variation for the charge surface density, considering a square plane plate, and 16 axe subdivisions, as a function of the selected threshold.

Therefore, the variation of the threshold allowed a significant reduction in execution time without significantly changing the value of the surface charge density.

Moreover, it should be mentioned that the Cholesky decomposition method was also implemented [8].

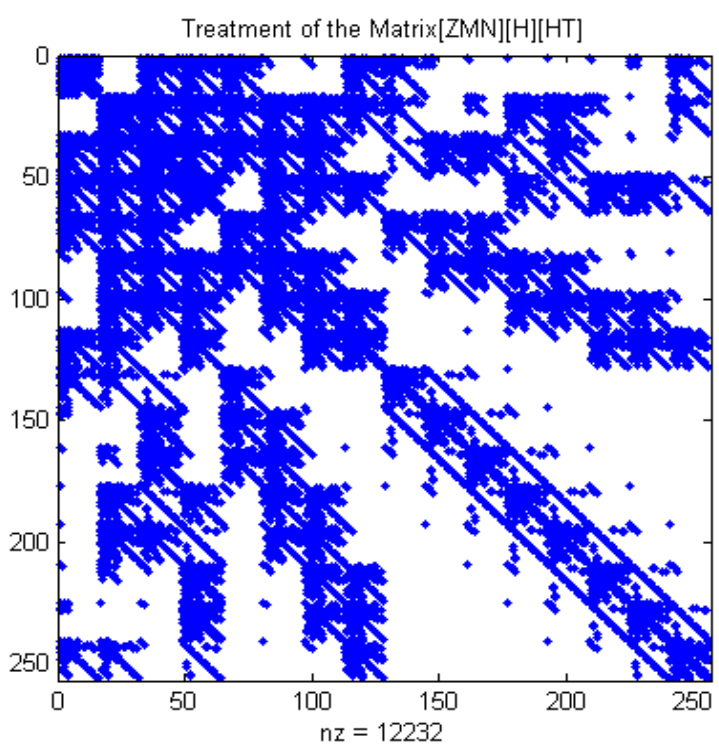

Fig. 11 Value of the threshold of $0.01 \%$ (23528 non-zero elements).

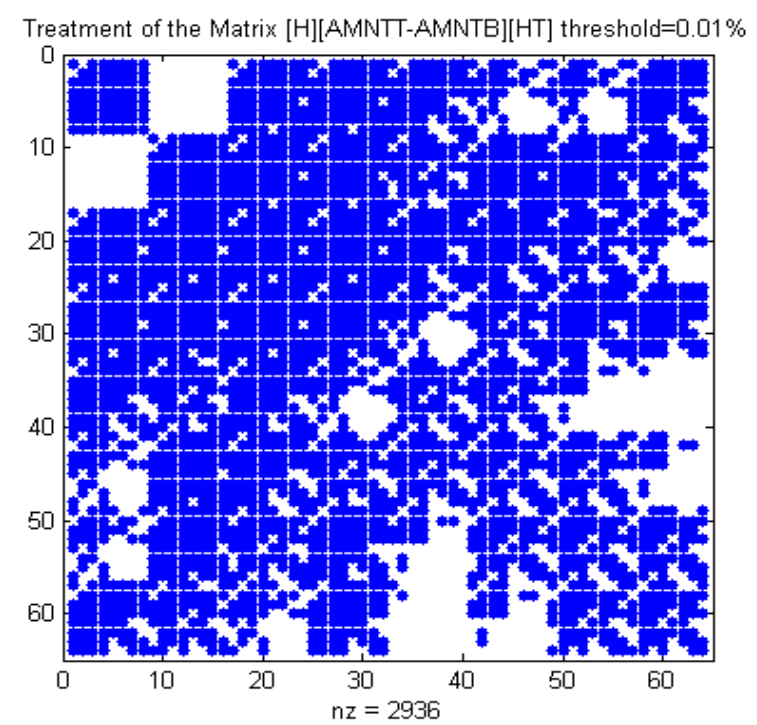

Fig. 12 Value of a threshold of $0.05 \%$ (12232 non-zero elements). 


\section{Mathematical Modeling for Determination the Surface Charge Density and Eddy Current Problem Using the Haar Wavelet}

Table 5 Computing time(s) as a function of the axe subdivisions and of the adopted threshold level.

\begin{tabular}{lllll}
\hline \multirow{2}{*}{ Subdivision } & \multicolumn{4}{c}{ Threshold levels (\%) } \\
\cline { 2 - 5 } & 0.00001 & 0.01 & 0.05 & 0.1 \\
\hline $16 \times 16$ & 0.27 & 0.21 & 0.16 & 0.12 \\
$32 \times 32$ & 25.486 & 11.49 & 4.516 & 2.073 \\
\hline
\end{tabular}

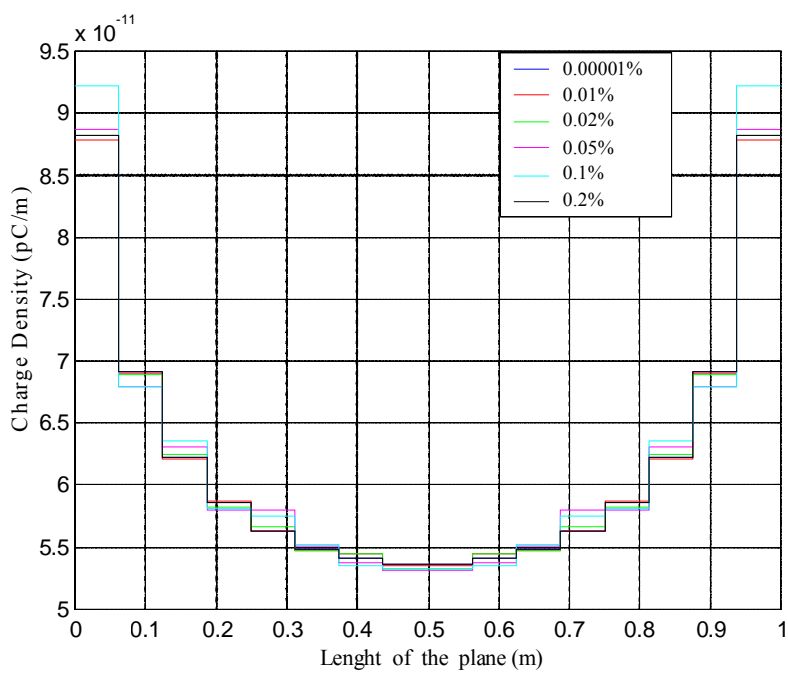

Fig. 13 Variation of the charge surface density as a function of a selected threshold.

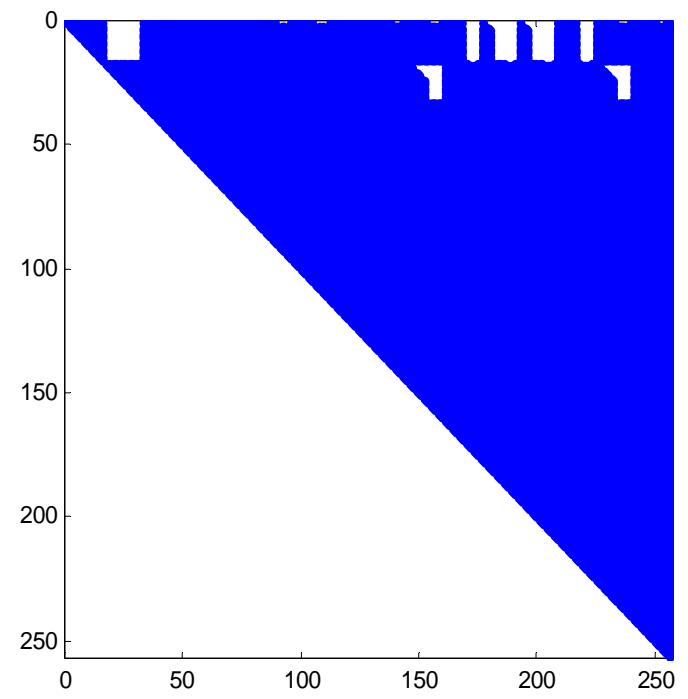

Fig. 14 Matrix configuration after applying the Cholesky decomposition for the threshold equal to $0.01 \%$.

Fig. 14 represents the matrix configuration after applying it, assuming a threshold level equal to $0.01 \%$. In this case, approximate increase of $64 \%$ was obtained in the null value element of the matrix.

Regarding the computational performance, the average computing time decreased from 0.21 to 0.02 (s), for 16 axe subdivision, and a reduction time from 11.49 to $0.351(\mathrm{~s})$.

\subsection{Eddy Current Problem}

In the application here presented, a copper conductor with the conductivity of $1.72(\mu \Omega \mathrm{cm})$ and resistivity of $100 \%$ as shown in Table 6 [20].

Fig. 15 shows the reactions of the electromagnetic field and the involved energy considering the influence between the charges using the developed program.

Therefore, the final equation for each one of the elements that compose the current matrix can be expressed by:

$$
\begin{aligned}
& A(x, y)=1-\frac{j \omega \mu \gamma}{4 \pi} * h^{2} * \\
& * a_{j} b_{j} \int_{-a}^{a} \int_{-b}^{b} \ln \left[\phi(x, y)\left(\sqrt{\left(x_{m}-x_{n}\right)^{2}+\left(y_{m}-y_{n}^{\prime}\right)^{2}}\right)\right] d x d y+ \\
& +\sum_{j=-\infty}^{\infty} \sum_{k=-\infty}^{\infty} a_{j, k} b_{j, k} * \\
& * \int_{-a}^{a} \int_{-b}^{b} \ln \left[\psi_{j, k}^{(H)}(x, y)\left(\sqrt{\left(x_{m}-x_{n}\right)^{2}+\left(y_{m}-y_{n}\right)^{2}}\right)\right] d x d y
\end{aligned}
$$

Table 6 Material characteristics.

\begin{tabular}{lll}
\hline Material type & $\begin{array}{l}\text { Resistance } \\
(\mu \Omega \mathrm{cm})\end{array}$ & Conductivity (\%) \\
\hline Aluminum (99.9) & 2.65 & 64.84 \\
Bronze & 12 & 14 \\
Copper & 1.72 & 100 \\
Nickel & 37 & 4.5 \\
Gold & 2.36 & 76 \\
\hline & & \\
\hline z: & & \\
\hline
\end{tabular}

Fig. 15 Electromagnetic field simulation. 


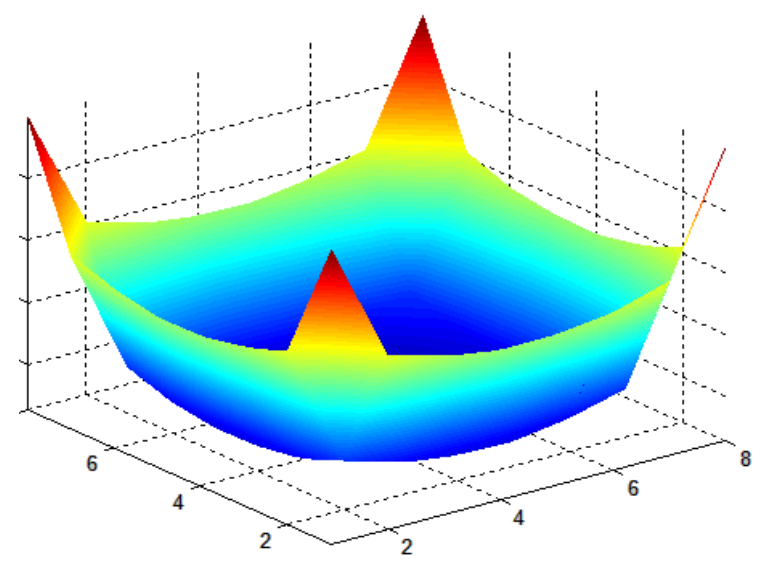

Fig. 16 Superficial charge distribution.

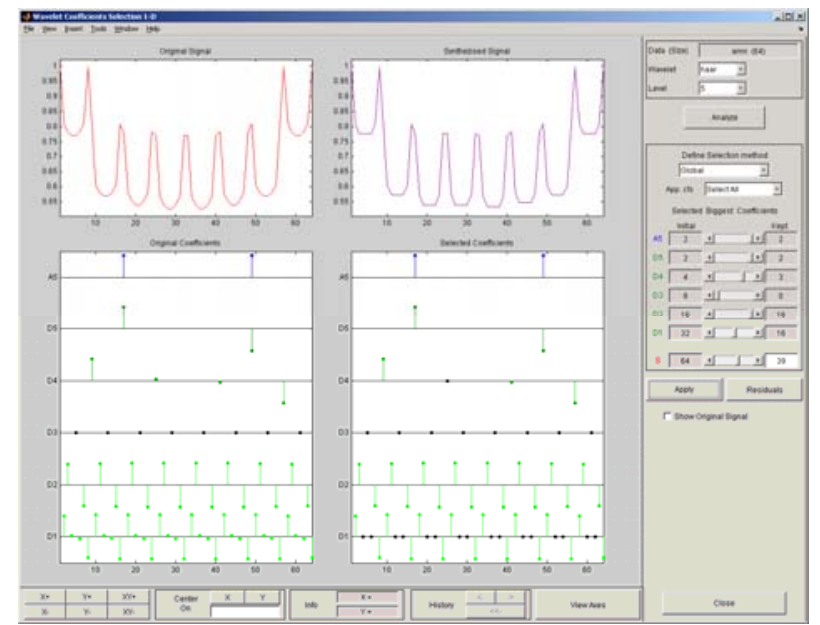

Fig. 17 Wavelet coefficients as a function of the resolution level.

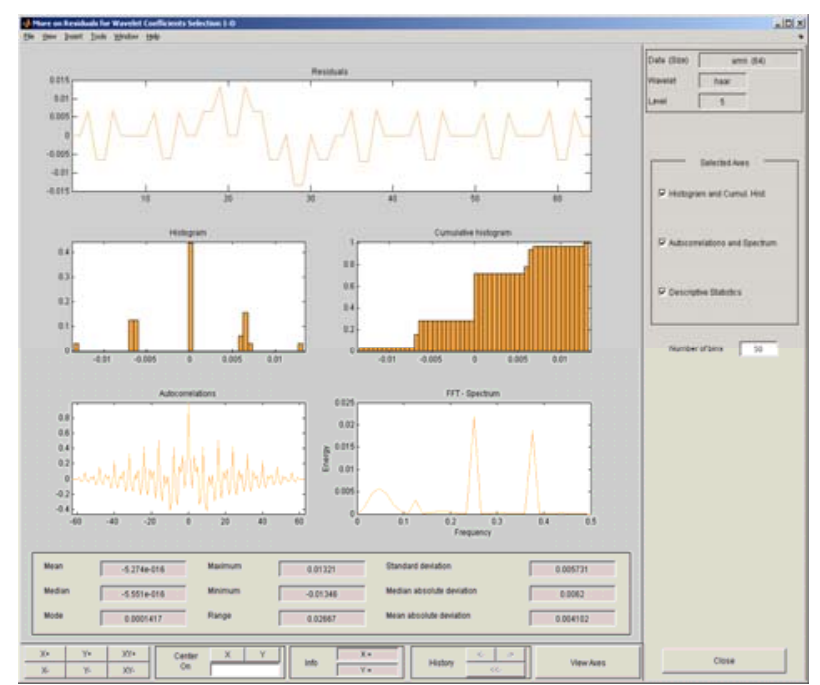

Fig. 18 Statistical data of the usage of the Haar wavelet with a level 5 resolution.

The solution of the previous equation can be obtained by using the expression $\left[a_{\mathrm{mn}}\right] *[\mathrm{Coef}]=\left[U_{0}\right]$
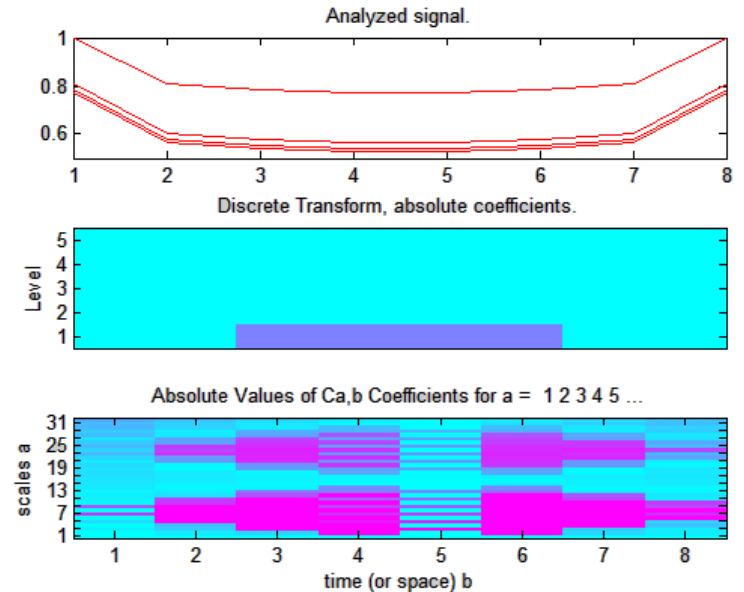

Fig. 19 Superficial charge distribution with different resolution levels.

$[21,22]$.

Fig. 16 shows the superficial charge distribution on the conductor, taking into consideration the effects of losses.

Fig. 17 was obtained through the use of the application toolbox and shows the results of the coefficients in relation to the several resolution levels. Through appropriate commands toolbox can obtain the numerical values of the coefficients in the application [23].

Fig. 18 shows the statistical data for a $0.01 \%$ threshold with level 5 resolution.

Fig. 19 shows several the coefficients in different resolution levels from matrix $a_{\mathrm{mn}}$.

\section{Conclusions}

This article has simply a series of applications of wavelets, such as the surface density in a finite straight wire and a flat plate, and the determination of eddy currents using the pulse and as a expansion function of the Haar wavelet.

The proposed methodology permits the determination of the available numerical coefficients in the application as a function of the resolution level, this way avoiding the complex solution of the inner product, usually composed of double integrals that do not possess a immediate solution.

By performing the product of the current matrix by 
the Haar wavelet $\left[a_{\mathrm{mn}}\right][$ Coefficients $][$ Haar $]=$ $\left[U_{0}\right][$ Haar $]$ and in some cases reductions in execution time of up to $40 \%$ has been achieved.

With this reduction in run time no significative variation in the $a_{\mathrm{mn}}$ elements that could compromise the final results has been found.

Although the proposed application is relatively simple, the presented methodology is likely to be applied to problems of greater complexity, such as a refinement can be achieved in energy in locking electric motors, cardiac signals, transmission lines, electromagnetic compatibility, financial market, corrosion or thermal treatment, neurological treatments and etc.

\section{References}

[1] Harrington, R. F. 1968. Field Computation by Moment Methods. New York: Macmillan Company.

[2] Clayton, P. R., and Syed, N. A. 1998. Introduction to Electromagnetic Fields.1st ed., New York: McGraw-Hill.

[3] Constantine, A. B. 1989. Advanced Engineering Eletromagnetics. 2nd ed., New York: John Wiley \& Sons.

[4] Harrington, R. F. 1961. Time-Harmonic Electromagnetic Fields. New York: Graw-Hill.

[5] Phillips, B. L. 1962. "A Technique for the Numerical Solution of Certain Integral Equations of the Second Kind." Journal of the ACM 9 (1): 84-97.

[6] Liang, J., Elangovan, S., and Devotta, J. B. X. 1999. “A Wavelet Multiresolution Analysis Approach to Fault Detection and Classification in Transmission Lines." Elsevier Computer Physics Communications 327-32.

[7] Mallat, S. 1996. "Wavelets for a Vision." In Proceedings of the IEEE 84 (4): 604-14.

[8] Cohen, A., Kovacevic, J. 1996. "Wavelets: The Mathematical Background." In Proceedings of the IEEE
84 (4): 514-22.

[9] Morettin, P. A. 1999. Ondas e Ondaletas. 1st ed., São Paulo: Edusp, 1-55.

[10] Morettin, P. A. 1997. $7^{\circ}$ Escola de Séries Temporais e Econometria. 1st ed., São Paulo: Edusp, 20-34.

[11] Newland, D. E. 1993. Random Vibrations Spectral and Wavelet Analysis. Addison Wesley Longman, 315-33.

[12] Aboufadel, E., and Schlicker, S. 1999. Discovering Wavelets. John Wiley \& Sons, 1-42.

[13] Kriezis, E. E., Stavaros, M. P., and Tegopoulos, J. A. 1992. "Eddy Currents: Theory and Applications." In Proceedings of the IEEE, 80 (10).

[14] Lopez, L. A. N. M. 2003. Transformadas de Wavelet e Lógica Fuzzy na Inspeção por Eddy-Current em Tubos de Geradores de Vapor de Centrais Nucleares, Tese de Doutorado,Universidade de São Paulo, USP, Brasil.

[15] Stoll, R. L. 1974. The Analysis of Eddy Currents. Clarendon Press.

[16] Kaitec, 2004. The 14th Kori Unit 4 Steam Generator Tube Eddy Current Examination. Final Report.

[17] Belardi, A. A., Cardoso, J. R., and Sartori, C. F., 2003. "Wavelets Application in Electrostatic and Their Computing Aspects." Electric and Magnetic Fields 43-4.

[18] Belardi, A. A., Cardoso, J. R., and Sartori, C. F. 2004. "Application of Haar's Wavelets in the Method to Solve Electrostatic Problems." Compel 23 (3): 606-12.

[19] Datta, B. N. 1995. Numerical Linear Algebra and Applications. 1st ed., New York: Brooks/Cole Publishing Company, 222-5.

[20] KPS, 2005. The 5th Ulchin Unit 4 Steam Generator Tube Eddy Current Examination. Final Report.

[21] Bossavit, A. 1990. A Numerical Approach to Transient Nonlinear Eddy Current Problems in Applied Electromagnetic in Materials, Elsevier.

[22] Salon, S., and Peng, J. P. 1994. "Three Dimensional Eddy Currents Using a Four Component Finite Element Formulation." IEEE Transactions on Magnetics.

[23] Palm, W. 2003. Introduction to Matlab 7 and Simulink for Engineers. McGraw-Hill, 55-97. 